\title{
Minimally invasive postoperative analgesia for pain relief after minimally invasive surgical procedures: the role of local anesthetic infusion
}

\author{
M. Beaussier
}

Received: 13 June 2012/ Accepted: 9 August 2012/Published online: 31 August 2012

(C) Springer-Verlag 2012

Surgery is increasingly moving toward minimally invasive procedures that lead to less tissue injury, less operative stress for the patient and less postoperative pain, allowing for patients to have a faster recovery than after conventional surgical approaches. Colorectal surgery is now widely performed by laparoscopy and is one of the most well-documented examples of this concept of "minimally invasive surgery." Anesthetic and analgesic strategies should evolve accordingly. All of the items that need to be controlled in order to make patients suitable for faster hospital discharge are mentioned in the Enhanced Recovery After Surgery (ERAS) Program, established by European experts involved in this process [1]. Although epidural analgesia (EA) remains one of the cornerstones of the ERAS program, the risks and benefits of this technique should be reevaluated in light of the development of multimodal analgesia, and other loco-regional alternative techniques, as well as recent pathophysiological concepts. Indeed, several studies have reported a very small benefit of EA after laparoscopic colorectal surgery [2, 3]. Furthermore, interesting recent data have emphasized the involvement of visceral nociceptive input, especially afferent fibers in the peritoneum, in the stress and pain response, induced by abdominal surgery [4]. It has been suggested that at least a part of these visceral afferents are transmitted directly along the vagal nerve, without passing through the spinal pathway, which raises some questions about the ability of EA to control them. This is supported by clinical trials showing that direct intraperitoneal [5] or

\section{Beaussier ( $\square)$}

Department of Anesthesia and Intensive Care,

St-Antoine Hospital, Assistance Publique, Hôpitaux de Paris,

Université Pierre et Marie Curie, Paris 6, France

e-mail: marc.beaussier@sat.aphp.fr preperitoneal wound infusions [6] would provide additional benefits when used in combination with epidural analgesia.

From this perspective, the study by Moore et al. [7] evaluating the use of surgical site catheter analgesia for pain relief after laparoscopic colorectal resection is meaningful. A continuous infusion of $8 \mathrm{ml} / \mathrm{h}$ ropivacaine $0.5 \%$ was delivered through an epidural catheter placed between muscular and subcutaneous layers for $72 \mathrm{~h}$. It is shown that this form of analgesia did not have significant beneficial effects on pain relief or opiate consumption, when compared to placebo. Factors that could explain how these negative results may have occurred were investigated by Rowlingson [8] some years ago, and it should be kept in mind that a large component of pain after laparoscopic abdominal surgery originates from surgical wound [9]. Catheter location is one of the most important issues to consider, with placement under the fascia being more effective than more superficial positions [10]. Epidural catheters are fenestrated over a very short length, so that the assumption made by the authors about the homogeneous diffusion of the local anesthetic solution between muscular and cutaneous layers is very unlikely. However, in accordance with the previous reports [11, 12], an improvement in respiratory function was noted in the group that received the ropivacaine infusion. This strongly suggests that wound infusion might still have beneficial effects on mobilization pain and/or neurogenic diaphragmatic dysfunction.

Nevertheless, pain relief after laparoscopic colorectal resection remains a critical issue because of our wish to provide patients with the most effective analgesic technique with the best tolerance and safety profiles. Blockade of intercostal nerves with a transversus abdominis plane (TAP) block has the ability to control the somatic component of pain and thereby to reduce opiate consumption 
and accelerate recovery [13]. Perioperative intravenous lidocaine is associated with beneficial effects on pain relief, opiate consumption and recovery [14]. Theoretically, continuous wound infiltration, in the preperitoneal position, could combine the effects of a parietal block, the blockade of several peritoneal afferents and the local anesthetic systemic effects. This hypothesis is certainly worth further study.

Conflict of interest M. Beaussier received honorarium for educational presentations on Surgical Site Catheter Analgesia from Baxter SA.

\section{References}

1. Lassen K, Soop M, Nygren J et al (2009) Consensus review of optimal perioperative care in colorectal surgery: enhanced recovery after surgery (ERAS) group recommendations. Arch Surg 144:961-969

2. Turunen P, Carpelan-Holmstrom M, Kairaluoma P et al (2009) Epidural analgesia diminished pain but did not otherwise improve enhanced recovery after laparoscopic sigmoidectomy: a prospective randomized study. Surg Endosc 23:31-37

3. Wongyingsinn M, Baldini G, Charlebois P, Liberman S, Stein B, Carli F (2011) Intravenous lidocaine versus thoracic epidural analgesia: a randomized controlled trial in patients undergoing laparoscopic colorectal surgery using an enhanced recovery program. Reg Anesth Pain Med 36:241-248

4. Kahokehr A, Sammour T, Srinivasa S, Hill AG (2011) Metabolic response to abdominal surgery: the 2-wound model. Surgery 149:301-304
5. Kahokehr A, Sammour T, Shoshtari KZ, Taylor M, Hill AG (2011) Intraperitoneal local anesthetic improves recovery after colon resection: a double-blinded randomized controlled trial. Ann Surg 254:28-38

6. Ozturk E, Yilmazlar A, Coskun F, Isik O, Yilmazlar T (2011) The beneficial effects of preperitoneal catheter analgesia following colon and rectal resections: a prospective, randomized, doubleblind, placebo-controlled study. Tech Coloproctol 15:331-336

7. Moore SE, Reid KC, Draganic BD, Smith SR (2012) Randomized clinical trial of ropivacaine wound infusion following laparoscopic colorectal surgery. Tech Coloproctol. doi: 10.1007/s10151-012-0845-2

8. Rowlingson $\mathbf{J}$ (2001) How can local anesthetic in the wound not help? Anesth Analg 92:3-4

9. Bisgaard T, Klarskov B, Rosenberg J, Kehlet H (2001) Characteristics and prediction of early pain after laparoscopic cholecystectomy. Pain 15:261-269

10. Gupta A, Favaios S, Perniola A, Magnuson A, Berggren L (2011) A meta-analysis of the efficacy of wound catheters for postoperative pain management. Acta Anaesthesiol Scand 55:785-796

11. Beaussier M, El'ayoubi H, Rollin M et al (2009) Parietal analgesia decreases postoperative diaphragm dysfunction induced by abdominal surgery: a physiologic study. Reg Anesth Pain Med 34:393-397

12. Chan SK, Lai PB, Li PT et al (2010) The analgesic efficacy of continuous wound instillation with ropivacaine after open hepatic surgery. Anaesthesia 65:1180-1186

13. Conaghan P, Maxwell-Armstrong C, Bedforth N et al (2010) Efficacy of transversus abdominis plane blocks in laparoscopic colorectal resections. Surg Endosc 24:2480-2484

14. Kaba A, Laurent SR, Detroz BJ et al (2007) Intravenous lidocaine infusion facilitates acute rehabilitation after laparoscopic colectomy. Anesthesiology 106:11-18 (discussion 5-6) 